\title{
The IFN- $\lambda$ Genetic Polymorphism Association With the Viral Clearance Induced by Hepatitis C Virus Treatment in Pakistani Patients
}

\author{
Imran Tipu ${ }^{1,2, *}$; Fiona Marriage ${ }^{2,3}$; Zia-ur-Rahman Farooqi ${ }^{2,4}$; Hazel Platt ${ }^{3}$; Muhammad \\ Amin Athar ${ }^{1}$; Philip John Day ${ }^{2,3}$; Andrea Short ${ }^{3}$ \\ ${ }_{1}^{1}$ Institute of Biochemistry and Biotechnology, University of the Punjab, Lahore, Pakistan \\ ${ }^{2}$ Manchester Institute of Biotechnology, University of Manchester, Manchester, UK \\ ${ }^{3}$ Centre for Integrated Genomic Medical Research, University of Manchester, Manchester, UK \\ ${ }^{4}$ National University of Science and Technology, Islamabad, Pakistan \\ *Corresponding Author: Imran Tipu, Institute of Biochemistry and Biotechnology, University of the Punjab, Lahore, Pakistan. Tel: +92-3214029804, E-mail: imran.tipu1@gmail.com \\ Received: September 27, 2013; Revised: December 10, 2013; Accepted: January 9, 2014
}

\begin{abstract}
Background: Polymorphisms in the interferon $\lambda(\operatorname{INF} \lambda)$ genes on chromosome 19 have been associated with clearance of hepatitis $C$ virus (HCV) induced by interferon and ribavirin therapy however there is no such data available for Pakistani patients with HCV infection.

Objectives: In this study, the effects of single nucleotide polymorphisms (SNPs) have been investigated in response to treatment with interferon- $\alpha$ and ribavirin in a cohort of 75 HCV genotype $3 a$ patients.

Patients and Methods: A total number of 50 SNPs from the Interferon $\lambda$ region on chromosome 19 were genotyped to investigate allelic associations with the treatment response in HCV type 3a patients. Thirteen SNPs were associated with HCV clearance, with the most significant alleles being RS8109886 (Fisher's $\mathrm{P}=0.0001$ ), RS8113007 (Fisher's $\mathrm{P}=0.0001$ ) and RS12979860 (Fisher's $\mathrm{P}=0.0002$ ).

Results: These SNPs were found to be the most suitable SNPs for predicting treatment response in the present study. These findings support those reported previously. This could be used to improve HCV treatment strategies and suggest that Pakistani patients should be genotyped for the relevant SNPs to identify the patients who are more likely to respond to interferon and ribavirin therapy.

Conclusions: This therapy is costly and can be accompanied by several adverse side-effects, hence pre-treatment prediction of patients who are most likely to benefit would have both economic and patient benefits in the long term.
\end{abstract}

Keywords: Polymorphism, Genetic; Polymorphism, Single Nucleotide; Antiviral Agents; Interferons; Ribavirin; Hepacivirus

\section{Background}

Hepatitis $\mathrm{C}$ virus (HCV) infection is one of the leading causes of chronic liver disease and has emerged as a global concern of public health, affecting about $3 \%$ of the world's population. Pakistan is the sixth most populated country in the world and has a HCV prevalence rate of 5.9\% (1). While there are different subtypes of HCV, genotype $3 a$ is the most common form in patients from Pakistan, with frequency ranging from $28.6 \%$ (2) to $89 \%$ (3) depending on the province (4). The clinical outcome of HCV infection is determined by the interplay between viral, environmental and host related factors (5). The host's immune system is the most important factor in viral persistence and innate immunity is the first line of defense, intervening with interferons and natural killer cells (6). This immune response is influenced by genetic polymorphisms in cytokines, their receptors (7) and the polymorphic genetic makeup of human populations. Genetic variations and T-cell responses are responsible for the outcome of HCV treatment (8). The most common type of genetic varia- tions are single nucleotide polymorphisms (SNPs) which occur approximately every 300 nucleotides in the human genome and can be used as biological markers for diseases or conditions. The majority of SNPs have no effect on health, but if SNPs are located within a gene or regulatory region, they can be functional in disease susceptibility and/or treatment response.

Studies have found that infected individuals with same HCV genotype differ in ability to spontaneously resolve infection, even if they have the same ethnic background with similar demographic features and are taking the same IFN- $\alpha$ /ribavirin therapy (9). The host genetics have been identified as key factors in the natural clearance of HCV and host SNPs have been already identified as associated factors in a number of studies in patients from different genetic backgrounds (Table 1). In particular, SNP RS12979860, present $3 \mathrm{~Kb}$ upstream of the Interleukin $28 \mathrm{~B}$ gene on chromosome 19 , has been associated with a three-fold change in response to treatment against HCV infection in AfricanAmerican and European cohorts (7). Another SNP from

Implication for health policy/practice/research/medical education:

The SNPs analyzed in this study showed significant association with response to the therapy which can be helpful for guiding the treatment of HCV patients in our population.

Copyright (c) 2014, Kowsar Corp.; Published by Kowsar Corp. This is an open-access article distributed under the terms of the Creative Commons Attribution License, which permits unrestricted use, distribution, and reproduction in any medium, provided the original work is properly cited. 
this region of chromosome 19, RS8099917, has been associated with HCV clearance in Australian (10) and Asian populations (11) (Table 1) and is located $8 \mathrm{~Kb}$ upstream of the IFNL3 gene. In humans, four functional type III IFN $\lambda$ (IFNL) genes are clustered around this region of chromosome 19encoding cytokines IL29 (IFNL1) , IL28A (IFNL2), IL28B (IFNL3) (12) and IFNL4 (13) and have a number of roles in controlling HCV infection including increasing the antiviral efficacy as a result of increased sub-saturating levels of IFN- $\alpha$ (14). IFN- $\lambda$ binds to the heterodimeric receptors IFN- $\lambda$ R 1 and IL10R2 forming interferon stimulated genes (ISGs) complex and initiating a signal transduction cascade (15) leading to up-regulation of several ISGs with antiviral effects (16). The IFN- $\lambda$ receptors are present on the plasmacytoid dendritic cells, peripheral B cells, hepa- tocytes and epithelial cells only so they can be used to target specific cell responses and can also help in avoiding adverse events of INF- $\alpha$ therapy (17). The role of SNPs present in the IFNL3 and IFNL4 genes in the spontaneous clearance of HCV was investigated, in addition to the associative role of SNPs present in the upand down-stream regions of genes encoding IFN- $\lambda$. This data could be of value for predicting the response to interferon and ribavirin therapy in Pakistani patients and though would be of economic and patient benefit in the long term.

\section{Objectives}

In this study, the effects of SNPs have been investigated in response to treatment with interferon- $\alpha$ and ribavirin in a cohort of 75 patients with genotype $3 \mathrm{a} \mathrm{HCV}$.

Table 1. Previous Studies Which Have Reported SNP Allelic Associations

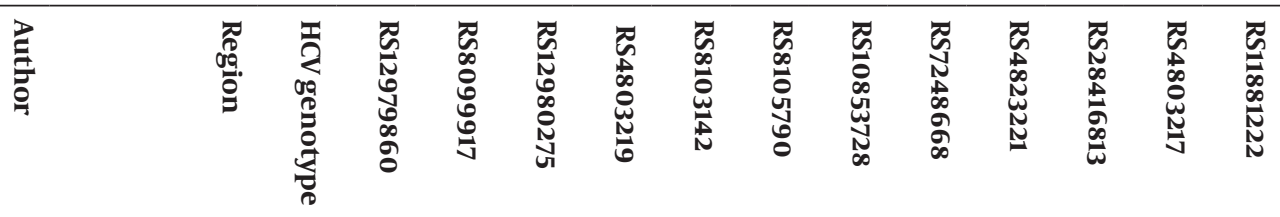

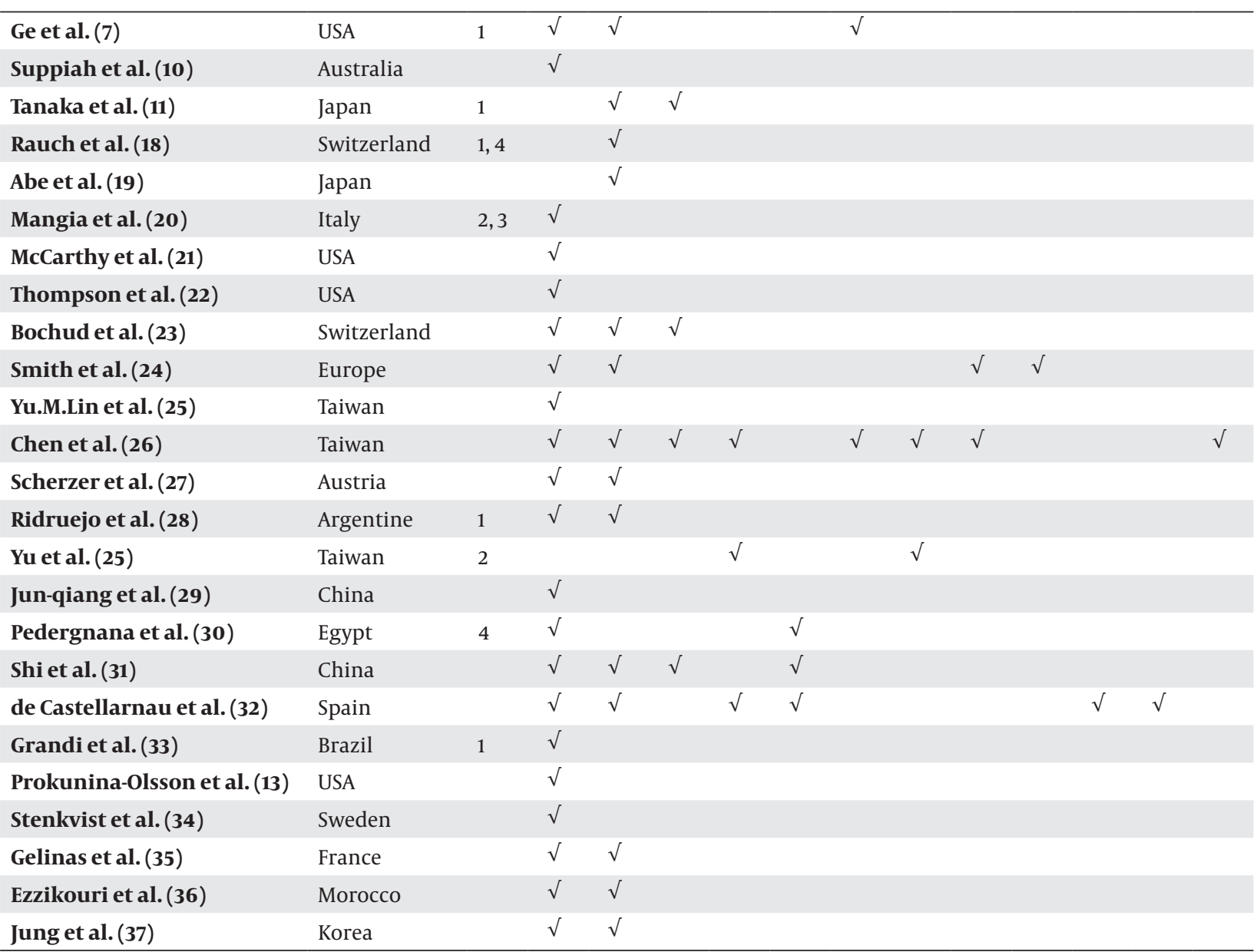


Tipu I et al.

\section{Patients and Methods}

\subsection{Selection and Description of Participants}

Following ethical approval from the Institutional Review Board (University of Punjab, Pakistan) written informed consent for genetic testing including IFN- $\lambda$ SNPs was obtained from each patient participating in the study. Patients were recruited from different areas of Punjab who visited National Genetics Laboratory, Lahore during March 2010 to May 2011. Patients displaying HCV like symptoms of infection ( $n=150$ ) were screened for HCV RNA using an in-house PCR detection technique, of the 150 patients screened, 100 were positive for HCVRNA and 75 were classified as genotype 3a. Each patient was interviewed and a structured questionnaire was completed to figure out the demographic data.

\subsection{Technical Information}

\subsubsection{HCV Detection}

HCV viral RNA was extracted from the patient's serum using a QIAamp viral RNA extraction kit (Qiagen). The HCV RNA was detected in 100 individuals using sequence specific primers designed to target the highly conserved 5' UTR sequence in HCV (Table 2). The viral genotype was detected by nested PCR using unique antisense primers which amplify the 5' conserved sequence of HCV within the genotype and their poor homology with the sequence derived from other genotypes (Appendix 1). Only 75 patients identified with the HCV genotype 3a were selected for further study, this comprised $75 \%$ of the patients screened and thus the study avoided the effect of HCV genotypes on therapy response.

\subsubsection{Treatment}

All patients received three million IU of IFN- $\alpha$ three times a week subcutaneously and ribavirin $(10 \mathrm{mg} /$ day/kg body weight) for a total period of six months. Doses of IFN- $\alpha$ were adjusted according to platelet and white blood cell counts of patients. Ribavirin dose varied according to the haemo- globin $(\mathrm{Hb})$ levels and weight of individual patients. The therapy response was monitored by alanine aminotransferase (ALT) and HCV RNA levels at the beginning and end of treatment. The HCV RNA quantification was performed by the Artus HCV RT-PCR (Qiagen) kit using a Rotor-Gene 3000 (Corbett Robotics, Australia) instrument.

\subsubsection{DNA Extraction}

Human genomic DNA was extracted from peripheral blood mononuclear cells using a QIAamp blood DNA mini kit (Qiagen). DNA was quantified using a NanodropND1000 spectrophotometer (lab technologies) and concentrations were normalized to $15 \mathrm{ng} / \mu \mathrm{L}$.

\subsubsection{SNP Selection and Genotyping}

In total, 50 SNPs were genotyped. Twenty five were from the coding region of the IL28B gene, 23 SNPs covered the 3 ' and 5' UTR's of all four IFN- $\lambda$ genes and the remaining two SNPs were from the newly discovered IFNL-4 gene. The details of SNPs are given in supplementary data (Appendix 2 and 3). Genotyping was performed using the iPLEX assay on a SEQUENOM MasSARRAY® platform. The primers were designed using the assay designing suite v1.0.1(SEQUENOM) (Appendix 4). An initial PCR amplified a 50-60 bp region flanking the polymorphic site. The product was treated with $1 \mathrm{U} / \mu \mathrm{L}$ of shrimp alkaline phosphatase at $37^{\circ} \mathrm{C}$ for 40 minutes to dephosphorylate any unincorporated dNTPs. The iPLEX reaction product was desalted using a cationic resin, pre-treated with acidic reagents, for optimizing mass spectrophotometric analysis. The desalted iPLEX product was spotted on the SpectroCHIP using a Nano spotter (Sequenom) and loaded on to the mass spectrometer. Each spot was then subjected to a laser under vacuum by the matrix-assisted laser desorption ionization-time-of-flight(MALDI-TOF) method. Assays were designed to SNPs on chromosome 19q13.13 covering the region encoding the IFN- $\lambda$ genes. After genotyping, SNPs and samples were quality checked.

\begin{tabular}{|c|c|c|c|c|c|}
\hline SNPS & MAF & Responder MAF $(n=47)$ & Non-Responder MAF $(\mathbf{n}=\mathbf{2 8})$ & OR $(95 \% \mathrm{CI})$ & P Value \\
\hline RS8109886 & 0.41 & 0.32 & 0.44 & $3.6(1.9-6.5)$ & 0.0001 \\
\hline RS8113007 & 0.25 & 0.19 & 0.33 & $3.6(1.9-6.5)$ & 0.0001 \\
\hline RS12979860 & 0.3 & 0.23 & 0.41 & $3.1(1.7-5.3)$ & 0.0002 \\
\hline RS11665818 & 0.38 & 0.29 & 0.5 & $2.9(1.6-5.3)$ & 0.0003 \\
\hline RS955155 & 0.33 & 0.26 & 0.38 & $2.9(1.6-5.1)$ & 0.0004 \\
\hline RS688187 & 0.31 & 0.27 & 0.38 & $2.7(1.5-4.7)$ & 0.0011 \\
\hline RS4803217 & 0.3 & 0.25 & 0.38 & $2.7(1.5-4.7)$ & 0.0011 \\
\hline RS8105790 & 0.19 & 0.16 & 0.25 & $2.6(1.4-4.6)$ & 0.0022 \\
\hline RS4803221 & 0.22 & 0.16 & 0.27 & $2.6(1.4-4.6)$ & 0.0022 \\
\hline RS8099917 & 0.19 & 0.16 & 0.25 & $2.6(1.4-4.6)$ & 0.0022 \\
\hline RS7248668 & 0.19 & 0.16 & 0.25 & $2.6(1.4-4.6)$ & 0.0022 \\
\hline RS12972991 & 0.22 & 0.17 & 0.3 & $2.5(1.4-4.5)$ & 0.0024 \\
\hline RS11671087 & 0.41 & 0.32 & 0.5 & $2.2(1.2-3.9)$ & 0.0130 \\
\hline
\end{tabular}

a Abbreviations: CI, confidence interval; MAF, minor allele frequency; OR: odds ratio. 
Tipu I et al.

\subsubsection{SNP Quality Controlled}

SNPs were excluded from the analyses if the call rate $<$ $90 \%$, Minor Allele Frequencies $<0.05$ and the cohort (responders + non-responders) was not in Hardy-Weinberg equilibrium (HWE, P < 0.05). Samples were excluded if the call rate was less than 90\%. Call rate, Hardy-Weinberg equilibrium, minor allele frequencies, allelic and haplotypic associations and linkage disequilibrium (LD) were performed using BC|GENE version 3.5-087 software (Biocomputing Platforms, Sweden) whilst Microsoft Excel was used for the determination of means and averages.

\subsection{Statistics}

\subsubsection{Association Analyses}

Association of the genetic variants and spontaneous HCV clearance, was determined using logistic regression. The major alleles (as RS12979860 C) were compared with minor alleles (rs12979860 T) in statistical analyses to determine odds ratios (OR) and 95\% confidence intervals (CI 95\%).

\subsubsection{Linkage Disequilibrium and Haplotypic Analysis}

Linkage disequilibrium between marker loci was assessed and haplotypic blocks were constructed using BC|GENE version 3.5-087 software (Biocomputing platforms, Sweden) and Haploview 4.2 (http://www.broadinstitute.org/haploview/haploview).

\subsubsection{Treatment Response}

The effectiveness of IFN- $\lambda$ loci SNPs was estimated for predicting the treatment response by comparing the sensitivity, specificity, positive predictive value (PPV) and negative predictive value (NPV) for minor allele homozygotes. The most clinically useful parameter to investigate the treatment failure is PPV.

\section{Results}

\subsection{Demographics}

Out of 75 patients with genotype 3a HCV enrolled into the study, 46 were male and 29 were female. The virological response was monitored by quantification of HCV RNA at the beginning and at the end of the six months period of the therapy revealing that $63 \%$ of subjects (47) showed Sustained Virological Response (SVR) and 37\% (28) patients were HCV RNA positive at the end of therapy. It also emerged that $75 \%$ of the patients were infected with HCV genotype 3a. These results were consistent with a recent review (4) showing the predominance of genotype 3a in the Pakistani population. The base line demographic, virological and clinical features of patients are shown in Table 3.

\subsection{Sample and SNP Quality Control}

We analyzed the region of $\sim 62.4 \mathrm{~kb}$ (Chr 19, nucleotide positions, 39719200-39781600; build GRCh37.p10) containing 50 SNPs (Tables 2 and 4 ) present in the IFN- $\lambda$ loci. Out of 50 SNPs, one failed the quality control (QC) criteria and was excluded from the analyses (SNP RS11881222 call rate $=80 \%$; all other samples satisfied the inclusion criteria $(>90 \%$ call rate, HWE $>0.05$ ). Twenty four SNPs present in the coding region of the IL28B gene were monomorphic in the studied Pakistani population and were therefore excluded from allelic association and haplotype analysis.

Table 3. Demographic and Clinical Characteristics of the Responders and Non-responders to Interferon and Ribavirin Therapy Against HCV Infection ${ }^{\text {a }}$

\begin{tabular}{|c|c|c|c|c|}
\hline & Responders & Range & Non Responder & Range \\
\hline Number of Patients, No. (\%) & $47(63)$ & & $28(37)$ & \\
\hline Average Age, $y$ & 43 & $(21-60)$ & 48 & $(28-63)$ \\
\hline \multicolumn{5}{|l|}{ Gender } \\
\hline Male & 30 & & 16 & \\
\hline Female & 17 & & 12 & \\
\hline \multicolumn{5}{|l|}{ Laboratory parameters } \\
\hline $\mathrm{Hb}, \mathrm{g} / \mathrm{dL}$ & 12.7 & $(8.2-16.4)$ & 12.8 & $(7.1-17.1)$ \\
\hline WBC, $10 \times 9 / \mathrm{L}$ & 5.64 & $(2.8-11)$ & 5.84 & $(3.3-9.4)$ \\
\hline PLT, $10 \times 9 / \mathrm{L}$ & 232 & $(93-402)$ & 165 & $(67-287)$ \\
\hline ALT, IU/L & 63 & $(15-224)$ & 93 & $(38-235)$ \\
\hline HCV-RNA, KIU/mL, Initial & 1200 & $(125-9900)$ & 1034 & $(146-5000)$ \\
\hline HCV-RNA, KIU/mL, End of treatment & below threshold & below threshold & 2647 & $(120-9800)$ \\
\hline
\end{tabular}

a Abbreviations: ALT, alanine transaminase; Hb, Haemoglobin; PLT: platelets; WBC: white blood cells. 
Tipu I et al.

\subsection{Allelic Association}

The allelic association revealed that a region of $\sim 39 \mathrm{~Kb}$ (Chr 19, nucleotide positions, 39729450-39768250; build GRCh37. p10) containing 13 polymorphic SNPs in Pakistani population is strongly associated (Fisher's P value $=0.0003-0.0130$ ) with spontaneous clearance and for all of these SNPs, spontaneous HCV clearance was more common with the major alleles. The most significant results were obtained with RS8109886 (Odds ratio of presenting HCV clearance [OR] for C vs. A = 3.6 [95\% CI:1.9-6.5] Fisher's P = 0.0001), RS8113007 (A vs. T OR = 3.6 [1.9-6.5]; Fisher's $P=0.0001)$ and RS12979860 (C vs. T OR=3.1 [1.7-5.3]; Fisher's $\mathrm{P}=0.0002)$. Among individuals, taking RS12979860 as an example, the proportion of HCV clearance was much higher in samples with major allele (80\% SVR) as compared to minor T allele (34\% SVR). The as- sociation analysis of response to treatment by IFN- $\lambda$ SNPs is described in Table 2.

\subsection{Linkage Disequilibrium}

Estimation of linkage disequilibrium was performed between 23 polymorphic IFN- $\lambda$ region SNPs, which revealed three haplotypic blocks: haplotype block I, of eight Kb, included eight SNPs (RS35790907, RS12972991, RS12980275, RS12982533, RS8105790, RS688187, RS4803217and RS12979860) in strong linkage disequilibrium $\left(\mathrm{r}^{2} \geq 0.85\right)$ haplotype block II, of 4Kb included seven SNPs (RS4803221, RS1549928, RS10853727, RS109886, RS8113007, RS8099917, RS7248668) in strong linkage disequilibrium $\left(\mathrm{r}^{2} \geq 0.95\right)$ and block III contained just two SNPs (RS1671087 and RS11665818) lying approximately $6 \mathrm{~kb}$ apart from each other and in strong linkage disequilibrium $\left(\mathrm{r}^{2} \geq 0.85 \%\right)$ (Figure 1 ).

\begin{tabular}{|c|c|c|c|c|c|}
\hline Haplotype & Frequency, \% & Responders, \% & Non-responders, \% & OR $(95 \% \mathrm{CI})$ & P Value \\
\hline AAATTGCCCATCATG & 58.3 & 66.0 & 44.7 & $2.37(1.34-4.20)$ & 0.0028 \\
\hline TCGCCAATGATATGA & 14.0 & 12.8 & 17.9 & $0.68(0.31-1.48)$ & 0.3286 \\
\hline AAATTGCCCATAATA & 9.60 & 7.40 & 14.0 & $0.46(0.18-1.2)$ & 0.106 \\
\hline TCGCTAATCGCATTG & 8.00 & 4.20 & 12.5 & $0.28(0.09-0.89)$ & 0.022 \\
\hline TAGCCAATGGTATGA & 5.30 & 3.20 & 7.10 & $0.41(0.10-1.64)$ & 0.194 \\
\hline AAATTGCTCATAATA & 2.00 & 3.20 & 1.90 & $1.52(0.25-9.27)$ & 0.650 \\
\hline
\end{tabular}

$\mathrm{a}$ The odds ratio has been calculated as carrying of haplotype vs. not carrying the haplotype.

b The frequency of six haplotypes in responders and non-responders for a haplotype block covering 13 Kb IFN- $\lambda$. The SNP order is RS35790907, RS12972991, RS12980275, RS12982533, RS8105790, RS688187, RS4803217, RS12979860, RS4803221, RS1549928, RS10853727, RS8109886, RS8113007, RS8099917 and RS7248668.

Figure 1. Analysis of Pairwise Linkage Disequilibrium (LD) Plot of IFN- $\lambda$ Region

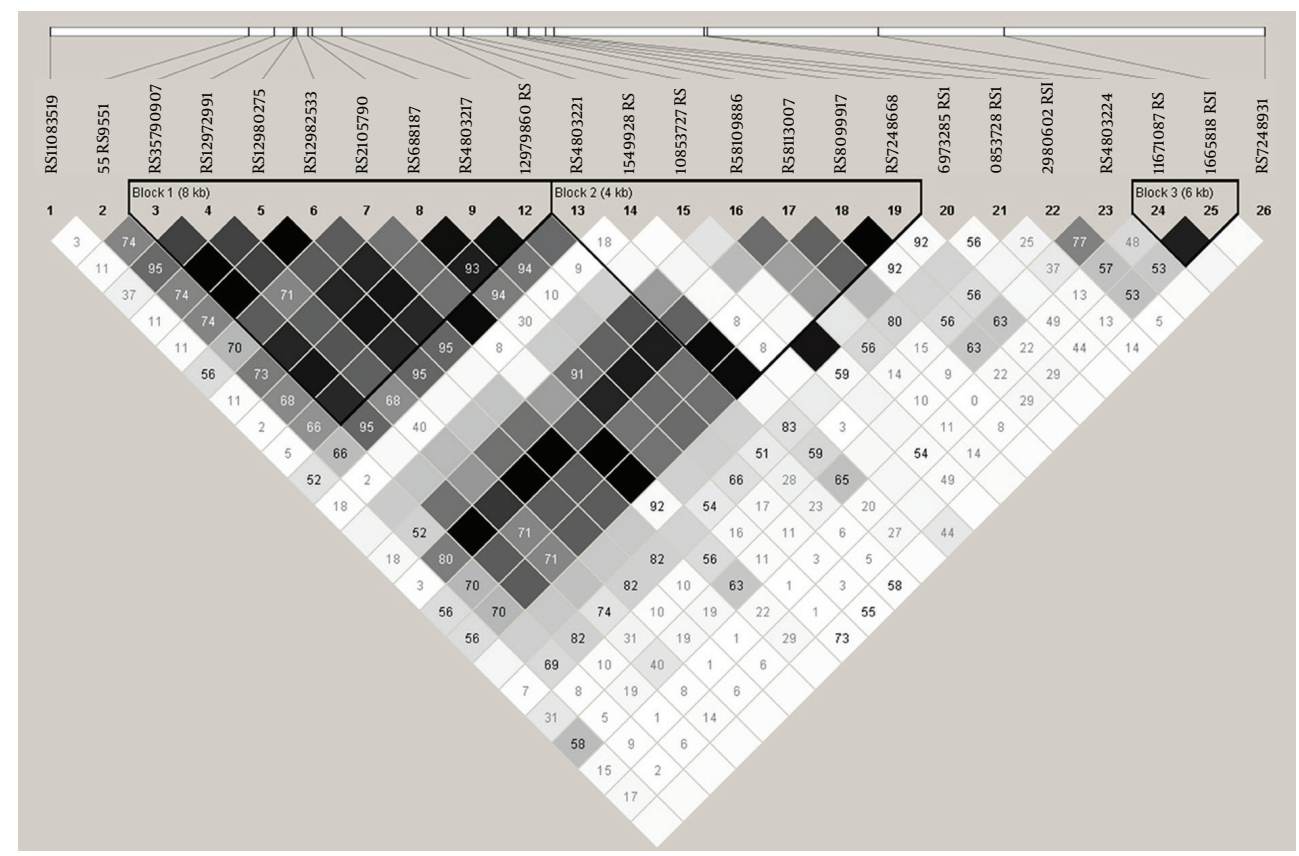

The linkage disequilibrium between the 17 SNPs in three LD blocks is shown. The red coloured squares represent $\mathrm{r}^{2}=1.0$ and blue coloured squares represent $\mathrm{r}^{2} \leq 0.01$. 


\subsection{Haplotype Analysis}

A total number of 6 haplotypes were investigated comprising of 15 SNPs using the Haploview (MIT/Harvard/ Brod Institute), among which haplotype one (AAATTGCCCATCATG) comprising of major alleles of 14 SNPs (RS35790907, RS12972991, RS12980275, RS12982533, RS8105790, RS688187, RS4803217, RS12979860, RS4803221, RS1549928, RS10853727, RS8109886, RS8113007, RS8099917 and RS7248668) had most significant association (OR = 2.37, 95\% CI $=1.34-4.20, \mathrm{P}=2.8 \times 10-3$ ) with therapy response in comparison with other detected haplotypes. The minor allele frequencies of each haplotype in responders and non-responders to the therapy with their odd ratios are shown in Table 1.

\subsection{Treatment Response}

The three highly associated SNPs with the treatment response; RS8109886 (PPV of 89\%, $95 \% \mathrm{CI}=81.17$ 94.37), RS8113007 (PPV of 74\%, $95 \% \mathrm{CI}=64.27-82.26$ ) and RS12979860 (PPV of 74\%, $95 \% \mathrm{CI}=64.27-82.26$ ) are also best indicators for predicting the treatment response. The sensitivity, specificity, prevalence, NPV and PPV of the IFN- $\lambda$ loci SNPs has been shown in Supplementary Appendix 5.

\section{Discussion}

The treatment of patients with HCV is based on clinical, demographic and virological characteristics of the disease, which are helpful from a population perspective but these baseline parameters are not suitable for predicting the treatment response in HCV patients infected with the most common genotype, 3a. Two SNPs have been most frequently associated with viral clearance across all HCV genotypes in different populations of the world: RS8099917 and RS12979860 (Table 1) and efforts have been largely directed at determining which of them is most likely to be more suitable for establishing the most useful diagnostic test for predicting treatment. Genotype 3a is the most common genotype of HCV infections in Pakistan $(4,38)$. In a new cohort of 75 type 3a Pakistani patients SNPs in the up-and down-stream regions of IFN- $\lambda$ and SNPs from IFNL3 and IFNL4 with known association to $\mathrm{HCV}$ clearance in other patient populations, were genotyped (Table 1). The allelic associations of four SNPs that have been reported previously in a number of populations were confirmed here (RS8105790, RS12979860, RS8099917 and RS7248668, Table 1) and a novel associations in Pakistani patients was identified (Table 2). The most significant SNPs (RS8109886 and RS8113007) detected by the present this in addition to six other SNPs have not been reported previously to have any association with HCV clearance in other populations and could be relevant to patients of Pakistani origin, although this requires follow-up studies to be fully confirmed.

Five SNPs reported in the literature were excluded from this study (RS4803219, RS8103142, RS4823221, RS28416813 and RS11881222). SNP RS11881222 failed our QC and was excluded for a low call rate $(<80 \%)$ but the other five SNPs were not included because the Sequenom primer design software was unable to design suitable primers and probes for them. Excluding these SNPs from our study could represent missed associations in Pakistani patients and constitute additional analyses in this cohort and in future studies to determine whether they have any role in HCV clearance in Pakistani patients as well as the ones reported in patients from Taiwan, Spain, China and Europe (Table 1). None of the SNPs associated with HCV clearance in this study were in coding regions; but were located in regions up-or down-stream of genes or in the 3' or 5'UTR. This suggests that they have a regulatory function rather than directly affecting protein structure. The 13 SNPs associated with HCV clearance in this study formed 6 haplotypes, of which the major alleles of SNPs RS8109886, RS8113007, RS12979860 and RS8099917 were all present on haplotype I, the haplotype with the highest Odds Ratio for predicting the treatment response (Table 4). The role of these SNPs has been established as having effects on the binding of different transcription factors and alterations of methylation sites resulting in reduced expression of IL28B, and up-regulation of ISGs in the responder haplotypes in response to IFN- $\alpha$ stimulation therapy (24) while IL28B non-responders have high ISG expression in infected hepatocytes, and that high ISG levels independently predicts poor response to the therapy (39). HCV clearance is a complex process, dependent on the type of HCV infection and the host's immunityrelated genetic factors. Some SNPs associated with HCV clearance in Pakistani patients are the same as those that have been detected to have associations in other cohorts too (Table 1) and suggest a common genetic background across multiple populations for HCV clearance. However, number of alleles identified in this study were unique to the present study which could suggest Pakistani-specific factors for HCV clearance, particularly for type 3a. It is important to consider, however, that this data comprised a small sample size and that repeating this study in a larger cohort could affect the findings and alter the outcome of some markers. For this reason, the data presented here should be interpreted with caution until it can be further verified. These findings, however, do support results widely reported from other populations were host genotype has been a proven factor in HCV clearance and treatment response (Table 1 ). Restricting this analysis to type 3a patients introduced a selection bias meaning if genotyping were to be introduced as a screening strategy, patients would require screening for HCV type prior to genotyping for treatment response. This selection strategy was chosen because type $3 a$ is the most common form of HCV in Pakistan and so represents the largest treatment group. Confirming the association of these SNPs and HCV clearance, in other HCV types requires further investigation. Tailoring treatments to target potential responders, 
Tipu I et al.

as opposed to generalized, universal treatment strategies, will be of economic benefit but, more importantly, will have substantial benefits for patients, as they would recover quicker and be less likely to require multiple 'trial-and-error' treatments. Data from the present study support the associations of SNPs (Table 2) present in the
IFN- $\lambda$ genes with HCV clearance after interferon and ribavirins combined therapy in Pakistani individuals infected with genotype $3 a$ and provide preliminary evidence to suggest patients should be genotyped for the relevant SNPs in order to predict drug response before starting therapy.

Appendix 1. The Details of Single Nucleotide Polymorphisms (SNPs) Present in the up- and Down-Stream Region of IFNL- $\lambda$ Genes. The Annotation of SNPs According to Their Position is Listed With Their Hardy-Weinberg Equilibrium P Values (HW p)

\begin{tabular}{|c|c|c|c|c|}
\hline SNP RS No. & SNP Position & Role of SNP & Alleles & HW p \\
\hline RS11083519 & chr19:39719263 & IFNL3 Downstream & A:T & 0.820 \\
\hline RS955155 & chr19:39729479 & IFNL3 Downstream & $\mathrm{C}: \mathrm{T}$ & 0.304 \\
\hline RS35790907 & chr19:39730755 & IFNL3 Downstream & A:T & 0.551 \\
\hline RS12972991 & chr19:39731747 & IFNL3 Downstream & $\mathrm{A}: \mathrm{C}$ & 0.831 \\
\hline RS12980275 & chr19:39731783 & IFNL3 Downstream & $A: G$ & 0.551 \\
\hline RS12982533 & chr19:39731904 & IFNL3 Downstream & $\mathrm{T}: \mathrm{C}$ & 0.551 \\
\hline RS8105790 & chr19:39732501 & IFNL3 Downstream & $\mathrm{T}: \mathrm{C}$ & 0.906 \\
\hline RS688187 & chr19:39732752 & IFNL3 Downstream & G:A & 0.394 \\
\hline RS4803217 & chr19:39734220 & IFNL4 Exon & C:A & 0.919 \\
\hline RS12979860 & chr19:39738787 & IFNL4 Intron & C:T & 0.173 \\
\hline RS4803221 & chr19:39739129 & IFNL3 Promoter & $\mathrm{C}: \mathrm{G}$ & 1.000 \\
\hline RS1549928 & chr19:39739709 & IFNL3 Promoter & $A: G$ & 0.625 \\
\hline RS10853727 & chr19:39740463 & IFNL3 Promoter & $\mathrm{T}: \mathrm{C}$ & 0.118 \\
\hline RS8109886 & chr19:39742762 & IFNL3 Promoter & C:A & 0.339 \\
\hline RS8113007 & chr19:39743103 & IFNL3 Promoter & $\mathrm{A}: \mathrm{T}$ & 0.225 \\
\hline RS8099917 & chr19:39743165 & IFNL3 Promoter & $\mathrm{T}: \mathrm{G}$ & 0.906 \\
\hline RS7248668 & chr19:39743821 & IFNL3 Promoter & G:A & 0.906 \\
\hline RS16973285 & chr19:39744696 & IFNL3 Promoter & C:T & 0.081 \\
\hline RS10853728 & chr19:39745146 & IFNL3 Promoter & $\mathrm{G}: \mathrm{C}$ & 0.387 \\
\hline RS12980602 & chr19:39752820 & IFNL2 Promoter & $\mathrm{T}: \mathrm{C}$ & 0.041 \\
\hline RS4803224 & chr19:39753014 & IFNL2 Promoter & $\mathrm{G}: \mathrm{C}$ & 0.976 \\
\hline RS11671087 & chr19:39761790 & IFNL2 Downstream & $\mathrm{T}: \mathrm{C}$ & 0.122 \\
\hline RS11665818 & chr19:39768216 & IFNL2 Downstream & G:A & 0.039 \\
\hline RS7248931 & chr19:39781583 & IFNL1 Promoter & $A: G$ & 0.812 \\
\hline
\end{tabular}

Appendix 2 . The Details of SNPs Located in IL28B Gene (IFNL-3) Listed According to Amino Acid Position. The Amino Acid Present in Normal (amino acid: context) and Change of Amino Acid Due to Allele Change (amino acid: SNP) Are Listed Accordingly

\begin{tabular}{|c|c|c|c|c|c|}
\hline SNP rs No. & $\begin{array}{l}\text { Amino Acid Posi- } \\
\text { tion. }\end{array}$ & SNP Position & $\begin{array}{l}\text { Amino Acid: } \\
\text { Context }\end{array}$ & Amino Acid: SNP & Allele Change \\
\hline RS200289435 & 1 & chr19:39735606 & Methionine & Threonine & ATG $\rightarrow$ ACG \\
\hline RS143935261 & 1 & chr19:39735607 & Methionine & Valine & ATG $\rightarrow$ GTG \\
\hline RS202126177 & 2 & chr19:39735603 & Threonine & Serine & ACC $\rightarrow$ ATC \\
\hline RS630388 & 2 & chr19:39735602 & Threonine & Threonine & $\mathrm{ACC} \rightarrow \mathrm{ACT}$ \\
\hline RS150569967 & 3 & chr19:39735601 & Glycine & Arginine & GGG $\rightarrow$ AGG \\
\hline RS199952257 & 57 & chr19:39735438 & Lysine & Arginine & $\mathrm{AAA} \rightarrow \mathrm{AGA}$ \\
\hline
\end{tabular}


Tipu I et al.

\begin{tabular}{llllll}
\hline RS202143862 & 72 & chr19:39735101 & Arginine & Cysteine & CGC $\rightarrow$ TGC \\
\hline RS145428712 & 101 & chr19:39734754 & Threonine & Methionine & ACG $\rightarrow$ ATG \\
\hline RS200889156 & 104 & chr19:39734744 & Valine & Valine & GTT $\rightarrow$ GTC \\
\hline RS148543092 & 108 & chr19:39734734 & Threonine & Alanine & ACC $\rightarrow$ GCC \\
\hline RS202101632 & 108 & chr19:39734732 & Threonine & Threonine & ACC $\rightarrow$ ACT \\
\hline RS201376760 & 114 & chr19:39734716 & Alanine & Threonine & GCC $\rightarrow$ ACC \\
\hline RS199801376 & 116 & chr19:39734708 & Glycine & Glycine & GGG $\rightarrow$ GGA \\
\hline RS200058568 & 123 & chr19:39734687 & Leucine & Leucine & CTT $\rightarrow$ CTC \\
\hline RS201605224 & 126 & chr19:39734678 & Leucine & Leucine & CTG $\rightarrow$ CTT \\
\hline RS199655870 & 132 & chr19:39734662 & Glutamine & Stop Codon & CAG $\rightarrow$ TAG \\
\hline RS149832972 & 133 & chr19:39734659 & Leucine & Phenylalanine & CTC $\rightarrow$ TTC \\
\hline RS139176035 & 134 & chr19:39734656 & Arginine & Tryptophan & CGG $\rightarrow$ TGG \\
\hline RS201566097 & 138 & chr19:39734544 & Glutamine & Stop Codon & CAG $\rightarrow$ TAG \\
\hline RS145946971 & 164 & chr19:39734465 & Lysine & Threonine & AAG $\rightarrow$ ACG \\
\hline RS143748522 & 179 & chr19:39734328 & Phenylalanine & Valine & TTC $\rightarrow$ GTC \\
\hline RS150748693 & 180 & chr19:39734325 & Arginine & Cysteine & CGC $\rightarrow$ TGC \\
\hline RS201746548 & 183 & chr19:39734314 & Threonine & Threonine & ACG $\rightarrow$ ACA \\
\hline RS200180353 & 191 & chr19:39734290 & Serine & Serine & AGC $\rightarrow$ AGT \\
\hline RS201888594 & 194 & chr19:39734282 & Leucine & Proline & CTG $\rightarrow$ CCG \\
\hline
\end{tabular}

Appendix 3 . The Primers Used for Detection and Genotyping of HCV. (HCF1: HCV Outer Forward Primer, HCR1: HCV Outer Reverse Primer, HCF2: HCV Internal Forward Primer, HCR2: HCV Internal Reverse Primer, HCGF1: HCV Genotype Outer Forward Primer, HCGR1: HCV Outer Reverse Primer, HCGF2: HCV Internal Forward Primer, Rest All Are Specific for Every HCV Genotype With Their Amplified Product Size Using Same Internal Primer

\begin{tabular}{|c|c|c|}
\hline Primer Name & 5'-3' Sequence & Product Size (bp) \\
\hline HCF1 & CCCTGTGAGGAACTACTGTCTTCACGC & 270 \\
\hline HCR1 & ACTCGCAAGCACCCTATCAGGCAGTAC & \\
\hline HCF2 & AAAGCGTCTAGCCATGGCG & 210 \\
\hline HCR2 & CACAAGGCCTTTCGCGACC & \\
\hline HCGF1 & TTGTGGTACTGCCTGATAGGG & 470 \\
\hline HCGR1 & GGATGTACCCCATGAGGATCG & \\
\hline HCGF2 & GTGCCCCGGGAGGTCTCGTAG & \\
\hline G1a & АСТССАССАACGATCTGACC & 129 \\
\hline G1b & AGCCTTGGGGATAGGTTGTC & 233 \\
\hline G1C & CTTACCCAAATTGCGTGACC & 391 \\
\hline G2a & CTCCGAAGTCTTCCTTGTCG & 190 \\
\hline G2b & AGCAAGTAAACTCCGCCAAC & 178 \\
\hline G2C & ACCGTTCGGAAGTTTTCCTC & 202 \\
\hline G3a & ACTCCACCAACGATCTGTCC & 258 \\
\hline G3b & AGCCTTGGGGATAAGGTGAC & 232 \\
\hline G3C & GTGACCGCTCGGAAGTCTTA & 197 \\
\hline G4a & CCGTAAAGAGGCCATGGATA & 288 \\
\hline G5a & AATCCGCACGTTAGGGTATG & 417 \\
\hline G6a & CAGCCTTCGCTTCCATAAAG & 300 \\
\hline
\end{tabular}




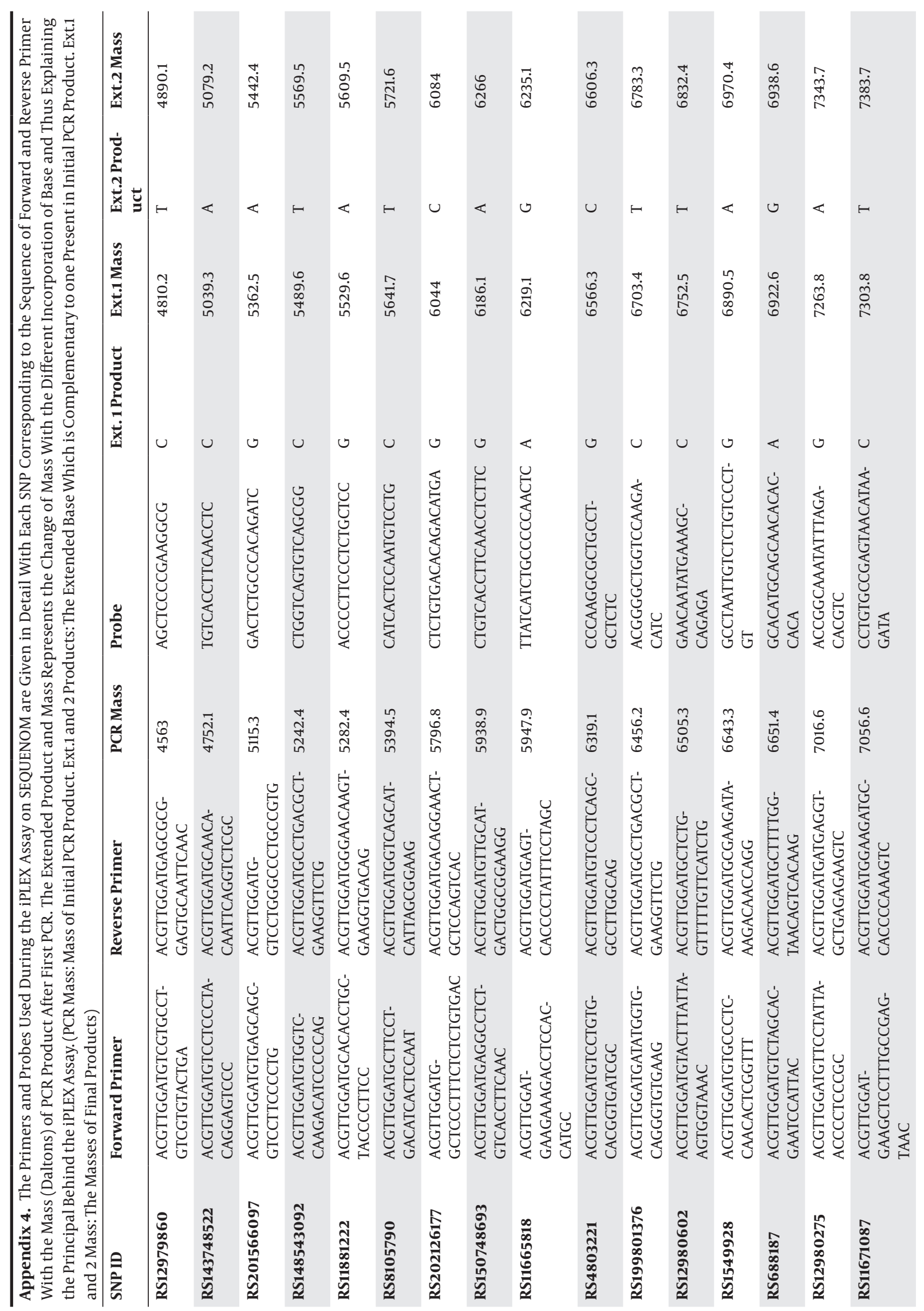




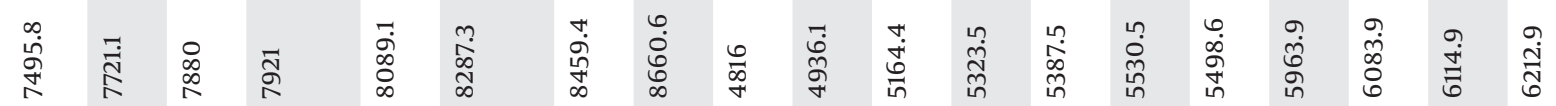

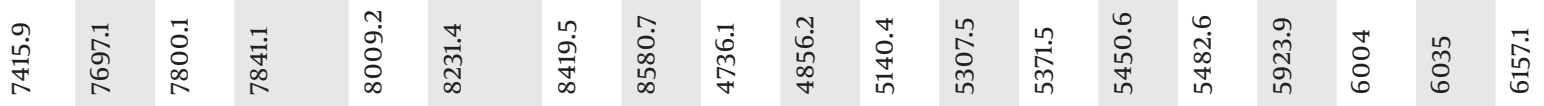

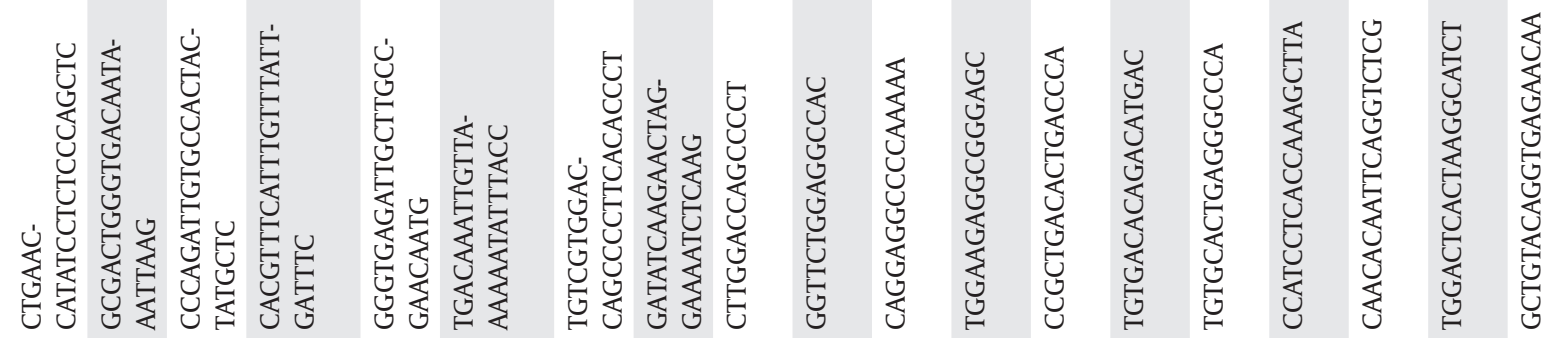

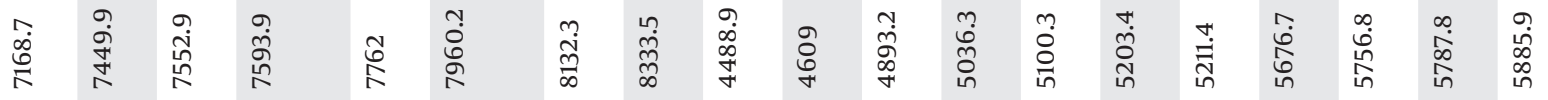

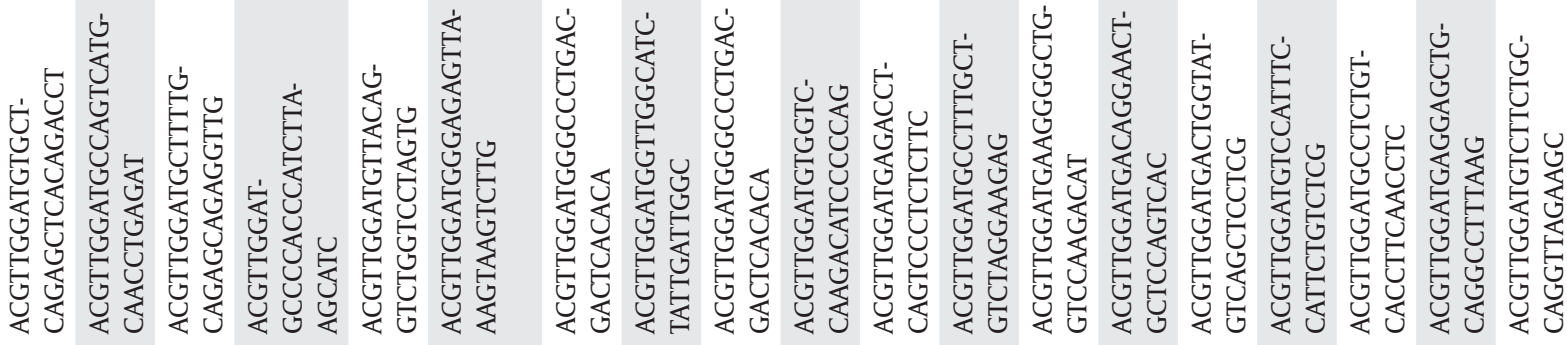

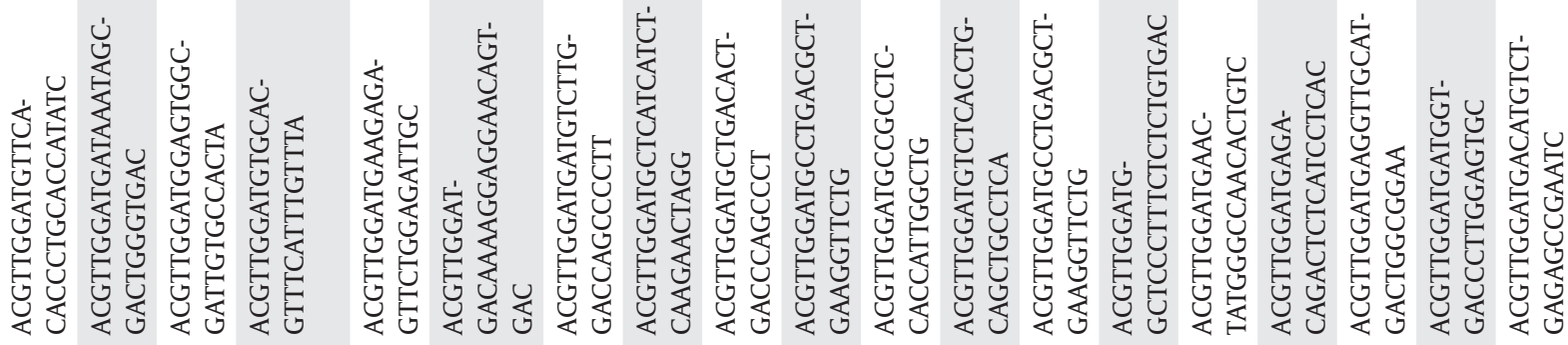

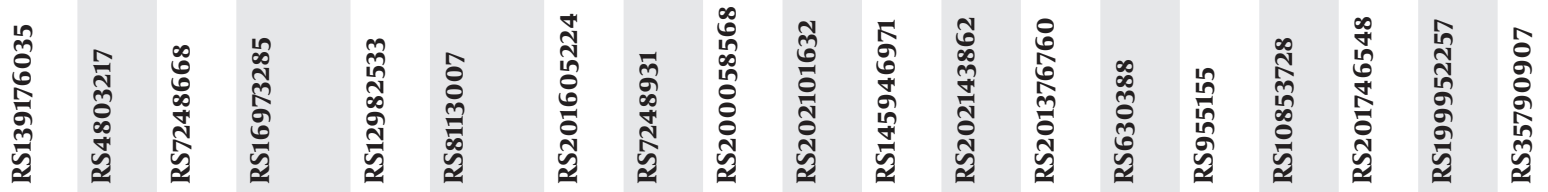




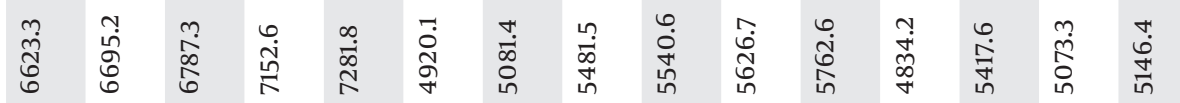

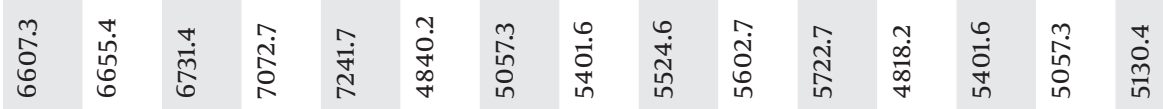

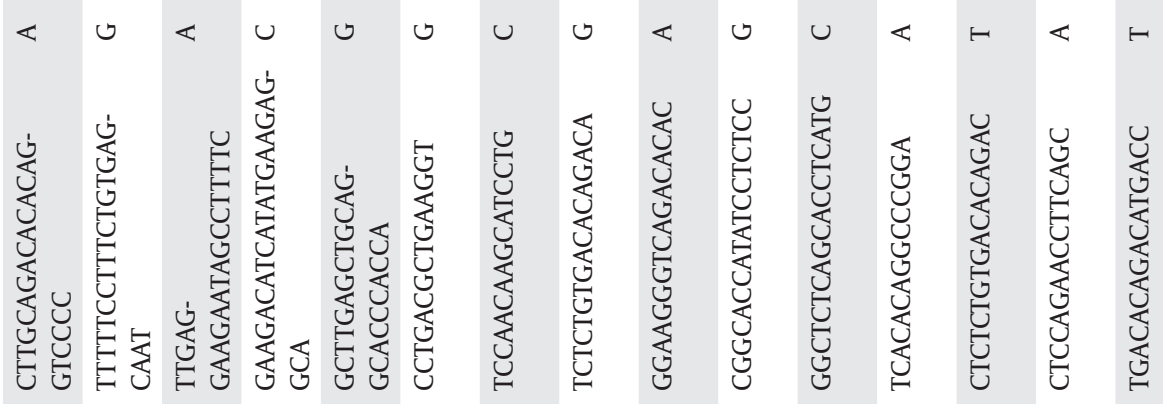

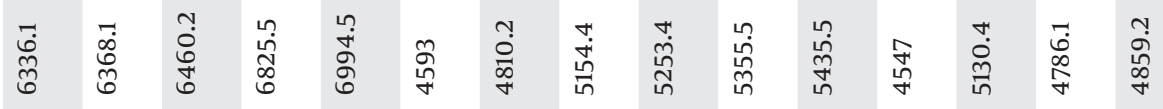

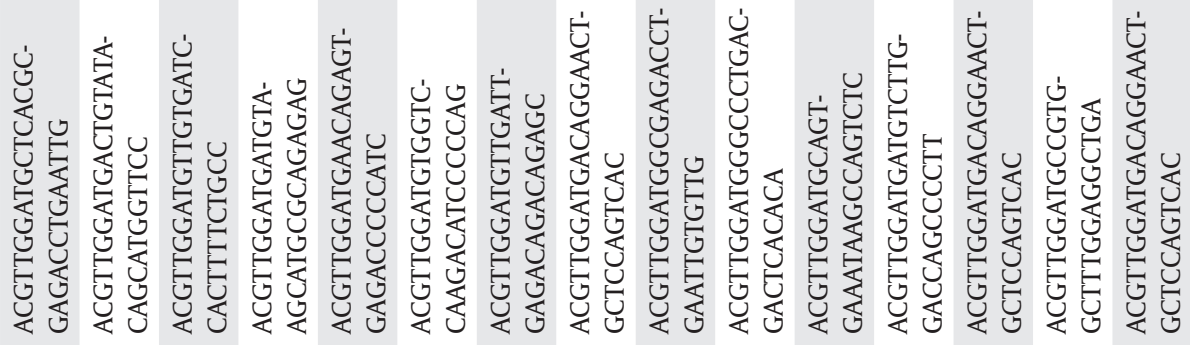

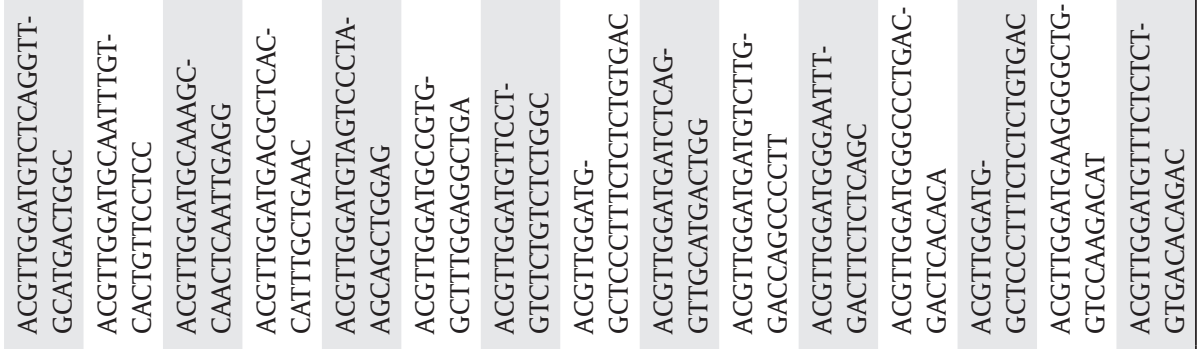

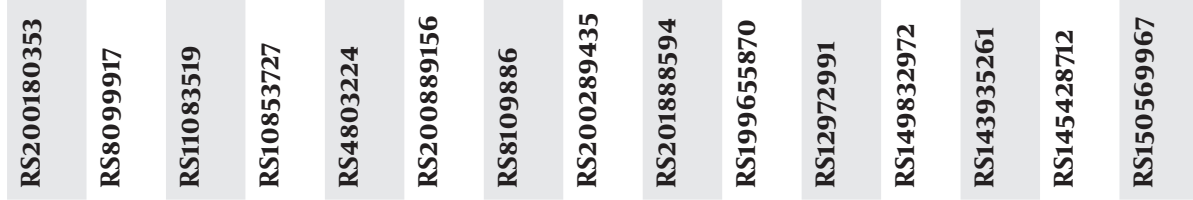


Tipu I et al.

\begin{tabular}{|c|c|c|c|c|c|}
\hline SNP & $\begin{array}{l}\text { Sensitivity, \% (95\% } \\
\text { CI) }\end{array}$ & $\begin{array}{l}\text { Specificity, \% } \\
(95 \% \mathrm{CI})\end{array}$ & $\begin{array}{l}\text { Prevalence, \% } \\
(95 \% \mathrm{CI})\end{array}$ & PPV, \% (95\%CI) & NPV, \% (95\%CI) \\
\hline RS955155 & $51.39(42.92-59.79)$ & $53.57(39.75-67.01)$ & $72.00(65.23-78.10)$ & $74.00(64.27-82.26)$ & $30.00(21.24-39.98)$ \\
\hline RS12972991 & $59.35(50.12-68.11)$ & $64.94(53.21-75.46)$ & $61.50(54.38-68.28)$ & $73.00(63.20-81.39)$ & $50.00(39.83-60.17)$ \\
\hline RS8105790 & $57.14(48.28-65.68)$ & $64.18(51.53-75.53)$ & $66.50(59.50-73.00)$ & $76.00(66.43-83.97)$ & $43.00(33.14-53.29)$ \\
\hline RS688187 & $52.48(43.91-60.95)$ & $55.93(42.40-68.84)$ & $70.50(63.66-76.72)$ & $74.00(64.27-82.26)$ & $33.00(23.92-82.26)$ \\
\hline RS4803217 & $52.48(43.91-60.95)$ & $55.93(42.40-68.84)$ & $70.50(63.66-76.72)$ & $74.00(64.27-82.26)$ & $33.00(23.92-82.26)$ \\
\hline RS12979860 & $56.92(47.95-65.57)$ & $62.86(50.48-74.11)$ & $65(57.95-71.59)$ & $74.00(64.27-82.26)$ & $44.00(34.08-54.28)$ \\
\hline RS4803221 & $51.23(42.80-60.04)$ & $53.23(40.12-66.01)$ & $69.00(62.09-75.33)$ & $71.00(61.07-79.64)$ & $33.00(23.92-43.12)$ \\
\hline RS8109886 & $60.09(52.55-68.92)$ & $79.63(66.47-89.35)$ & $73.00(66.28-79.02)$ & $89.00(81.17-94.37)$ & $43.00(33.14-53.29)$ \\
\hline RS8113007 & $52.48(43.91-60.95)$ & $55.93(42.40-68.84)$ & $70.05(63.66-76.72)$ & $74.00(64.27-82.26)$ & $33.00(23.92-43.12)$ \\
\hline RS8099917 & $42.01(34.47-49.83)$ & $6.45(0.98-21.26)$ & $84.50(78.73-89.22)$ & $71.00(61.07-79.64)$ & $2.00(0.30-7.05)$ \\
\hline RS7248668 & $42.01(34.47-49.83)$ & $6.45(0.98-21.26)$ & $84.50(78.73-89.22)$ & $71.00(61.07-79.64)$ & $2.00(0.30-7.05)$ \\
\hline RS11671087 & $59.35(50.12-68.11)$ & $64.94(53.21-75.46)$ & $61.50(54.38-68.28)$ & $73.00(63.20-81.39)$ & $50.00(39.20-81.39)$ \\
\hline RS11665818 & $62.30(53.07-70.91)$ & $69.23(57.76-79.19)$ & $61.00(53.87-67.80)$ & $76.00(66.43-83.97)$ & $54.00(43.74-64.01)$ \\
\hline
\end{tabular}

a Abbreviations: 95\% CI, 95\% confidence interval; PPV, Positive predictive value; NPV, Negative predictive value

\section{Acknowledgements}

We would like to thank the technical staff at CIGMR and National Genetics Laboratory, Lahore for making this study possible by contributing their professional skills. This study was supported by the Higher Education Commission Pakistan.

\section{Author' Contribution}

Conceived and designing the experiments: Philip Day, Fiona Marriage, Amin Athar, Imran Tipu; performed the experiments: Imran Tipu, Hazel Plat, Zia Farooqi, analysed the data: Andrea Short, Imran Tipu; wrote the paper: Imran Tipu, Philip Day, Andrea Short.

\section{Conflict of Interest}

We do not have any conflict of interest.

\section{Financial Disclosure}

Imran Tipu received financial assistance from Higher education commission of Pakistan to conduct this research.

\section{Funding/Support}

This study was the supported by international research support initiative program (IRSIP) grant code: IRSIP 21: BMS 38. By Higher education commission of Pakistan.

\section{References}

1. Lavanchy D. Evolving epidemiology of hepatitis C virus. Clin Microbiol Infect. 2011;17(2):107-15.

2. Rehman IU, Idrees M, Ali M, Ali L, Butt S, Hussain A, et al. Hepatitis $\mathrm{C}$ virus genotype $3 \mathrm{a}$ with phylogenetically distinct origin is cir- culating in Pakistan. Genet Vaccines Ther. 2011;9(1):2.

3. Azhar MA, Bukhari MH, Ghanni U, Khan A, Malik JI, Shah AH. Prevalence of hepatitis $C$ virus and its serotypes in Bahawalpur Division. Biomed. 2003;19:18-22.

4. Attaullah S, Khan S, Ali I. Hepatitis C virus genotypes in Pakistan: a systemic review. Virol J. 2011;8:433.

5. Amini M, Poustchi H. Hepatitis $\mathrm{C}$ virus spontaneous clearance: immunology and genetic variance. Viral Immunol.2012;25(4):2418.

6. Raulet DH. Interplay of natural killer cells and their receptors with the adaptive immune response. Nat Immunol. 2004;5(10):996-1002.

7. Ge D, Fellay J, Thompson AJ, Simon JS, Shianna KV, Urban TJ, et al. Genetic variation in IL28B predicts hepatitis C treatment-induced viral clearance. Nature. 2009;461(7262):399-401.

8. Cox AL, Netski DM, Mosbruger T, Sherman SG, Strathdee S, Ompad D, et al. Prospective evaluation of community-acquired acutephase hepatitis C virus infection. Clin Infect Dis. 2005;40(7):951-8.

9. Bonis PA. Clinical outcomes after hepatitis $\mathrm{C}$ infection from contaminated anti-D immune globulin. $N$ Engl J Med. 1999;341(10):763.

10. Suppiah V, Moldovan M, Ahlenstiel G, Berg T, Weltman M Abate ML, et al. IL28B is associated with response to chronic hepatitis $\mathrm{C}$ interferon-alpha and ribavirin therapy. Nat Genet. 2009;41(10):1100-4.

11. Tanaka Y, Nishida N, Sugiyama M, Kurosaki M, Matsuura K, Sakamoto N, et al. Genome-wide association of IL28B with response to pegylated interferon-alpha and ribavirin therapy for chronic hepatitis C. Nat Genet. 2009;41(10):1105-9.

12. Sheppard P, Kindsvogel W, Xu W, Henderson K, Schlutsmeyer S, Whitmore TE, et al. IL-28, IL-29 and their class II cytokine receptor IL-28R. Nat Immunol. 2003;4(1):63-8.

13. Prokunina-Olsson L, Muchmore B, Tang W, Pfeiffer RM, Park H, Dickensheets $\mathrm{H}$, et al. A variant upstream of IFNL3 (IL28B) creating a new interferon gene IFNL4 is associated with impaired clearance of hepatitis C virus. Nat Genet. 2013;45(2):164-71.

14. Marcello T, Grakoui A, Barba-Spaeth G, Machlin ES, Kotenko SV MacDonald MR, et al. Interferons alpha and lambda inhibit hepatitis $C$ virus replication with distinct signal transduction and gene regulation kinetics. Gastroenterology. 2006;131(6):1887-98.

15. Gad HH, Dellgren C, Hamming OJ, Vends S, Paludan SR, Hartmann R. Interferon-lambda is functionally an interferon but 
structurally related to the interleukin-10 family. J Biol Chem. 2009;284(31):20869-75.

16. Pagliaccetti NE, Eduardo R, Kleinstein SH, Mu XJ, Bandi P, Robek MD. Interleukin-29 functions cooperatively with interferon to induce antiviral gene expression and inhibit hepatitis $C$ virus replication. J Biol Chem. 2008;283(44):30079-89.

17. Sommereyns C, Paul S, Staeheli P, Michiels T. IFN-lambda (IFNlambda) is expressed in a tissue-dependent fashion and primarily acts on epithelial cells in vivo. PLoS Pathog. 2008;4(3).

18. Rauch A, Kutalik Z, Descombes P, Cai T, Di Iulio J, Mueller T, et al. Genetic Variation in IL28B Is Associated With Chronic Hepatitis C and Treatment Failure: A Genome-Wide Association Study. Gastroenterol. 2010;138(4):1338-45. e7.

19. Abe H, Ochi H, Maekawa T, Hayes CN, Tsuge M, Miki D, et al. Common variation of IL28 affects gamma-GTP levels and inflammation of the liver in chronically infected hepatitis $\mathrm{C}$ virus patients. JHepatol. 2010;53(3):439-43.

20. Mangia A, Thompson AJ, Santoro R, Piazzolla V, Tillmann HL, Patel $\mathrm{K}$, et al. An IL28B polymorphism determines treatment response of hepatitis C virus genotype 2 or 3 patients who do not achieve a rapid virologic response. Gastroenterology. 2010;139(3):821-1.

21. McCarthy JJ, Li JH, Thompson A, Suchindran S, Lao XQ, Patel K, et al. Replicated association between an IL28B gene variant and a sustained response to pegylated interferon and ribavirin. Gastroenterology. 2010;138(7):2307-14.

22. Thompson AJ, Muir AJ, Sulkowski MS, Ge D, Fellay J, Shianna KV, et al. Interleukin-28B polymorphism improves viral kinetics and is the strongest pretreatment predictor of sustained virologic response in genotype 1 hepatitis C virus. Gastroenterology. 2010;139(1):120-18.

23. Bochud PY, Bibert S, Negro F, Haagmans B, Soulier A, Ferrari C, et al. IL28B polymorphisms predict reduction of HCV RNA from the first day of therapy in chronic hepatitis C. J Hepatol. 2011;55(5):980-8.

24. Smith KR, Suppiah V, O'Connor K, Berg T, Weltman M, Abate ML, et al. Identification of improved IL28B SNPs and haplotypes for prediction of drug response in treatment of hepatitis $C$ using massively parallel sequencing in a cross-sectional European cohort. Genome Med.2011;3(8):57.

25. Yu ML, Huang CF, Huang JF, Chang NC, Yang JF, Lin ZY, et al. Role of interleukin-28B polymorphisms in the treatment of hepatitis C virus genotype 2 infection in Asian patients. Hepatology. 2011;53(1):7-13.

26. Chen JY, Lin CY, Wang CM, Lin YT, Kuo SN, Shiu CF, et al. IL28B genetic variations are associated with high sustained virological response (SVR) of interferon-alpha plus ribavirin therapy in Taiwanese chronic HCV infection. Genes Immun. 2011;12(4):300-9.

27. Scherzer TM, Hofer H, Staettermayer AF, Rutter K, Beinhardt S, Steindl-Munda P, et al. Early virologic response and IL28B polymorphisms in patients with chronic hepatitis $\mathrm{C}$ genotype
3 treated with peginterferon alfa-2a and ribavirin. $J$ Hepatol. 2011;54(5):866-71.

28. Ridruejo E, Solano A, Marciano S, Galdame O, Adrover R, Cocozzella D, et al. Genetic variation in interleukin-28B predicts SVR in hepatitis $C$ genotype 1 Argentine patients treated with PEG IFN and ribavirin. Ann Hepatol. 2011;10(4):452-7.

29. Xie JQ, Guo XY, Zhang XH, Lin BL, Xie DY, Gao ZL, et al. Relationship between the genetic variation in interleukin $28 \mathrm{~B}$ and response to antiviral therapy in patients with chronic hepatitis C. Chin Med J (Engl). 2012;125(13):2334-8.

30. Pedergnana V, Abdel-Hamid M, Guergnon J, Mohsen A, Le Fouler L, Theodorou I, et al. Analysis of IL28B variants in an Egyptian population defines the 20 kilobases minimal region involved in spontaneous clearance of hepatitis C virus. PLoS One. 2012;7(6).

31. Shi X, Pan Y, Wang M, Wang D, Li W, Jiang T, et al. IL28B genetic variation is associated with spontaneous clearance of hepatitis Cvirus, treatment response, serum IL-28B levels in Chinese population. PLoS One. 2012;7(5).

32. de Castellarnau M, Aparicio E, Parera M, Franco S, Tural C, Clotet $\mathrm{B}$, et al. Deciphering the interleukin $28 \mathrm{~B}$ variants that better predict response to pegylated interferon-alpha and ribavirin therapy in HCV/HIV-1 coinfected patients. PLoS One. 2012;7(2).

33. Grandi T, da Silva CM, Amaral KM, Picon PD, Costi C, da Fre NN, et al. Response to treatment in Brazilian patients with chronic hepatitis $C$ is associated with a single-nucleotide polymorphism near the interleukin-28B gene. Mem Inst Oswaldo Cruz. 2013;108(1):48-53.

34. Stenkvist J, Sonnerborg A, Weiland O. HCV RNA decline in chronic HCV genotype 2 and 3 during standard of care treatment according to IL28B polymorphism. J Viral Hepat. 2013;20(3):193-9.

35. Gelinas JF, Fabre T, Willems P, Leung RC, George J, Willems B, et al. IL28B SNP screening and distribution in the French Canadian population using a rapid PCR-based test. Immunogenetics. 2013;65(6):397-403.

36. Ezzikouri S, Alaoui R, Rebbani K, Brahim I, Fakhir FZ, Nadir S, et al. Genetic variation in the interleukin-28B gene is associated with spontaneous clearance and progression of hepatitis $C$ virus in Moroccan patients. PLoS One. 2013;8(1).

37. Jung YK, Kim JH, Ahn SM, Yang JW, Park SJ, Kim JW, et al. Role of interleukin 28B-related gene polymorphisms in chronic hepatitis $\mathrm{C}$ and the response to antiviral therapy in Koreans. J Clin Gastroenterol. 2013;47(7):644-50.

38. Aziz H, Raza A, Murtaza S, Waheed Y, Khalid A, Irfan J, et al. Molecular epidemiology of hepatitis $C$ virus genotypes in different geographical regions of Punjab Province in Pakistan and a phylogenetic analysis. Int Infect Dis. 2013;17(4):e247-53.

39. Honda M, Sakai A, Yamashita T, Nakamoto Y, Mizukoshi E, Sakai Y, et al. Hepatic ISG expression is associated with genetic variation in interleukin $28 \mathrm{~B}$ and the outcome of IFN therapy for chronic hepatitis C. Gastroenterology. 2010;139(2):499-509. 